Jurnal Media Pertanian Vol. 1 No. 2 Tahun 2016 Hal. 62 - 68

Media Komunikasi Hasil Penelitian dan Review Literatur Bidang Ilmu Agronomi

ISSN $2503-1279$

\title{
TANGGAP TANAMAN JAGUNG TERHADAP PEMBERIAN PUPUK PRODUK SAMPING CAIR PABRIK KELAPA SAWIT PLUS ZEOLIT
}

\author{
Ida Nursanti \\ Program Studi Agroteknologi, Fakultas Pertanian Universitas Batanghari \\ Jl. Slamet Riyadi-Broni, Jambi 36122 Telp. +62074160103 \\ email : ida_unbari@yahoo.co.id
}

\begin{abstract}
Liquid by product of palm oil pruduct Mills as an organic fertilizer to meet crop nutrient needs of corn and increase fertilizer efficiency. Utilization of zeolite can improve the quality of organic fertilizers, soil conditioners and water backup controller. The study aims to determine the effect of fertilizer of liquid product of palm oil mill plus zeolite on the growth of corn and determines that the liquid product of palm oil mill as a ferlizer plus zeolite can better influence the growth of corn plants that without zeolite. The study lasted for three months. Research using a completely randomized design, with 3 levels of treatment is treatment Side Liquid Product Mills useness. The treatments were without Side Liquid Product Mills plus zeolite (P0), Side Liquid Product Mills without zeolite $1000 \mathrm{ml}$ (P1), Side Liquid Product Mills $1000 \mathrm{ml}$ plus zeolite $10 \%$ (P2). Each treatment was repeated 3 times so that there are $3 \times 3=9$ experimental units. The results showed that the liquid manure of by products of palm oil mill plus zeolite may affect plant growth significantly, especially in the corn plant height, weight of wet canopy, root wet weight, levels of leaf $N$ and $P$ content of leaves. Liquid byproduct of palm oil mills plus $10 \%$ zeolite $1000 \mathrm{ml}$ dose of plant can better influence the growth of corn plants.
\end{abstract}

Keywords : Side Liquid Product Mills, Zeolit, Corn

\begin{abstract}
Abstrak
Produk Samping Cair Pabrik Kelapa Sawit (PSCPKS) sebagai pupuk organik dapat memenuhi kebutuhan unsur hara tanaman jagung dan meningkatkan efisiensi pemupukan. Pemanfaatan zeolit dapat meningkatkan kualitas pupuk organik, soil conditioner dan pengontrol cadangan air. Penelitian bertujuan untuk mengetahui pengaruh pemberian pupuk produk samping cair pabrik kelapa sawit plus zeolit terhadap pertumbuhan tanaman jagung dan menentukan bahwa pupuk produk samping cair pabrik kelapa sawit plus zeolit dapat lebih baik mempengaruhi pertumbuhan tanaman jagung dari pada pupuk produk samping cair pabrik kelapa sawit tanpa zeolit. Pelaksanaan penelitian berlangsung selama 3 bulan. Penelitian menggunakan Rancangan Acak Lengkap (RAL), dengan 3 taraf perlakuan merupakan perlakuan pemberian PSCPKS. Perlakuan yang diteliti adalah : tanpa PSCPKS plus zeolit (P0), PSCPKS tanpa zeolit $1000 \mathrm{ml}$ (P1), PSCPKS $1000 \mathrm{ml}$ plus zeolit 10\% (P2). Setiap perlakuan diulang 3 kali sehingga terdapat $3 \times 3=9$ unit percobaan. Hasil penelitian menunjukkan bahwa pupuk produk samping cair pabrik kelapa sawit plus zeolit dapat mempengaruhi pertumbuhan tanaman jagung secara signifikan terutama pada tinggi tanaman, bobot basah tajuk, bobot basah akar, kadar $\mathrm{N}$ daun dan kadar P daun. Produk samping cair pabrik kelapa sawit plus zeolit $10 \%$ dosis $1000 \mathrm{ml}$ tanaman $^{-1}$ dapat lebih baik mempengaruhi pertumbuhan tanaman jagung.
\end{abstract}

Kata kunci : PSCPKS, Zeolit, Jagung

\section{PENDAHULUAN}

Produk Samping Cair Pabrik Kelapa Sawit (PSCPKS) dapat digunakan sebagai pupuk organik yang dapat memenuhi kebutuhan unsur hara tanaman dan meningkatkan efisiensi pemupukan serta mendukung sistem pertanian organik low eksternal input 
Jurnal Media Pertanian Vol. 1 No. 2 Tahun 2016 Hal. 11 - 21

Media Komunikasi Hasil Penelitian dan Review Literatur Bidang Ilmu Agronomi

ISSN $2503-1279$

sustainable agriculture. Produk Samping Cair Pabrik Kelapa Sawit mengandung unsur $\mathrm{N}, \mathrm{P}, \mathrm{K}, \mathrm{Ca}, \mathrm{Mg}$, dan mengandung berbagai jenis mikrobia berguna sebagai penyedia hara dan pembenah tanah. Pemberian pupuk Produk Samping Cair Pabrik Kelapa Sawit pada tanah di areal perkebunan dapat meningkatkan $\mathrm{pH}$ tanah dari 5,39 menjadi 6,25, N total tanah meningkat sampai $46 \%$, P tersedia dari 7,778 ppm menjadi $224,78 \mathrm{ppm}, \mathrm{K}$ dari 0,098 me/100 menjadi $0,962 \mathrm{me} / 100, \mathrm{Mg}$ dari $0,326 \mathrm{me} / 100$ menjadi 2,563 me/100 (Widiastuti et al.,2006). Hasil penelitian Nursanti et al.(2013) diperoleh bahwa PSCPKS hasil pengolahan system IPAL kolam anaerob sekunder I memiliki kadar Ntotal 0,18\%, P-total 0,07\%, K 0,06\%, COD $10082 \mathrm{mg} / \mathrm{l}, \mathrm{BOD} 7333 \mathrm{mg} / \mathrm{l}$ dan nilai $\mathrm{pH}$ 6,1 .

Aplikasi PSCPKS dengan dosis $740 \mathrm{~m}$ L per polybag diinkubasi selama 2 minggu tanpa diberikan pupuk anorganik, memberikan hasil berat kering kedelai 18,49 g per tanaman (setara dengan 1,85 $\mathrm{t} \mathrm{ha}^{-1}$ ), tanaman tidak memperlihatkan defesiensi unsur hara serta pertumbuhan dan produksi nyata lebih tinggi dibandingkan dengan tanpa pemberian PSCPKS (Muzar, 2008).

Zeolit merupakan mineral yang bermuatan negatif, yang dapat dinetralkan oleh logam-logam alkali atau alkali tanah, memiliki pori-pori yang terisi ion-ion $\mathrm{K}, \mathrm{Na}, \mathrm{Ca}$, $\mathrm{Mg}$ dan molekul $\mathrm{H}_{2} \mathrm{O}$, sehingga memungkinkan terjadinya pertukaran ion dan pelepasan air secara bolak-balik. Selain sebagai penukar kation, zeolit juga berfungsi sebagai penyerap kation-kation yang dapat menyebabkan pencemaran lingkungan seperti $\mathrm{Pb}, \mathrm{Al}$, $\mathrm{Fe}, \mathrm{Mn}, \mathrm{Zn}$, dan $\mathrm{Cu}$. Adanya zeolit tersebut dapat mengurangi pencemaran lingkungan . Kundari et al. (2010) menjelaskan bahwa Limbah cair yang mengandung logam besi dan mangan dapat diolah dengan menggunakan zeolit, karena zeolit alam efektif sebagai adsorben limbah Fe dan Mn .

Vaulina (2002) menyebutkan, bahwa penggunan zeolit mampu menyerap logam berat pada limbah perairan seperti $\mathrm{Pb}, \mathrm{Hg}$ dan $\mathrm{Cd}$. Jabri (2008) menjelaskan bahwa zeolit dapat mengabsorpsi $\mathrm{CO}_{2}, \mathrm{H}_{2} \mathrm{~S}$ dan $\mathrm{NH}_{3}$, serta mengurangi hilang atau tercucinya unsur N. Mineral zeolit juga dapat dimanfaatkan dalam pengolahan limbah industri sebagai penyerap bau dan warna serta sebagai katalis seperti pada industri gula. Pemanfaatan zeolit di bidang pertanian selama ini adalah: bahan untuk meningkatkan kualitas pupuk organik, bahan campuran untuk membuat pupuk lambat tersedia, soil conditioner dan pengontrol cadangan air.

\section{METODE PENELITIAN}

Pelaksanaan penelitian dilakukan Lagan Ulu Kecamatan Geragai Kabupaten Tanjung Jabung Timur. Penelitian berlangsung selama 3 bulan. Bahan yang digunakan dalam penelitian ini adalah: tanah sulfat masam potensial yang diambil dari Desa Lagan Ulu Kecamatan Geragai Kabupaten Tanjung Jabung Timur Provinsi Jambi, terletak pada Koordinat Geografis $1^{\circ} 11^{\prime}$ 58,66" dan $103^{\circ} 44^{\prime} 6,1^{\prime \prime}$ produk samping Cair Pabrik Kelapa Sawit berasal dari PT. Sumbertama Nusa Pertiwi.

Penelitian ini dilakukan dengan metode eksperimen dan menggunakan Rancangan Acak Lengkap (RAL), dengan 3 taraf perlakuan merupakan perlakuan pemberian PSCPKS. Perlakuan yang diteliti adalah : tanpa PSCPKS plus zeolit (P0), PSCPKS tanpa zeolit $1000 \mathrm{ml}$ (P1), PSCPKS $1000 \mathrm{ml}$ plus zeolit 10\% (P2). Setiap perlakuan diulang $3 \mathrm{kali}$ sehingga terdapat $3 \times 3=9$ unit percobaan. 
Jurnal Media Pertanian Vol. 1 No. 2 Tahun 2016 Hal. 11 - 21

Media Komunikasi Hasil Penelitian dan Review Literatur Bidang Ilmu Agronomi ISSN $2503-1279$

Lahan penelitian terlebih dahulu dibersihkan dari gulma dan kotoran lainnya, lalu diolah dengan cara menggemburkan lahan menggunakan cangkul, dilanjutkan dengan pembuatan plot percobaan dengan ukuran $20 \mathrm{~m}$ x 9,8 m Ploting dilakukan sesuai dengan layout percobaan.

Penanaman dilakukan dengan menugal lahan yang telah digemburkan, kemudian memasukkan benih jagung Bisi-2 yaitu 2 benih per lubang tanaman yang sebelumnya benih direndam dalam air 10 menit, dengan jarak tanam $70 \mathrm{~cm} \times 25 \mathrm{~cm}$. Tiap perlakuan ditanam 12 tanaman sehingga tanaman berjumlah 12 × $9=108$ tanaman.

Pemupukan dasar dilakukan bersamaan dengan saat penanaman dengan dosis rekomendasi urea $200 \mathrm{~kg} \mathrm{ha}^{-1}$, TSP $125 \mathrm{~kg} \mathrm{ha}^{-1}$ dan KCl $50 \mathrm{~kg} \mathrm{ha}^{-1}$ (Raihan et al., 2004). Pemupukan dilakukan dengan cara ditugal disekitar tanaman dengan jarak $7 \mathrm{~cm}$ dari tanaman. Pemberian pupuk dasar ini dilakukan dengan dosis $25 \%$ rekomendasi. Perlakuan pemberian PSCPKS sesuai perlakuan dilakukakan 3 kali yaitu pada saat tanam, saat tanaman berumur 15 hari dan pada tanaman berumur 35 hari. PSCPKS diberikan dengan cara disiramkan merata ke tanah.

Pengamatan yang dilakukan terhadap pertumbuhan tanaman jagung terdiri dari : tinggi tanaman $(\mathrm{cm})$, bobot basah tajuk (g), bobot basah akar (g), kadar $\mathrm{N}$ daun (\%), dan kadar P daun (\%).

Data hasil pengamatan dianalisa dengan menggunakan analisis ragam. Untuk membandingkan rerata setiap peubah digunakan uji Duncan New Multiple Range Test (DNMRT) pada taraf $\alpha 5 \%$. Data hasil pengamatan dianalisa menggunakan bantuan program Excel Wordsheet dan Statistical Analisis System Versi 17.

\section{HASIL dan PEMBAHASAN}

Hasil analisis statistik pemberian produk samping cair pabrik kelapa sawit (PSCPKS) berpengaruh nyata terhadap semua peubah pertumbuhan tanaman pada peubah tinggi tanaman, bobot basah tajuk, bobot basah akar, kadar $\mathrm{N}$ daun dan kadar $\mathrm{P}$ daun. Tanaman yang diberi PSCPKS plus zeolite (P2) memberikan nilai peubah pertumbuhan yang lebih tinggi dibandingkan dengan tanaman yang diberi PSCPKS tanpa zeolite (P1) dan tanpa diberi PSCPKS (P0) seperti pada Gambar 1 sampai Gambar 5 .

Produk samping cair pabrik kelapa sawit plus zeolit dapat melepaskan unsur hara tersedia dan air yang diadsorpsinya secara perlahan apabila terjadi kondisi defisit unsur hara tersedia dan air, sehingga PSCPKS plus zeolit dapat membantu mempertahankan ketersediaan unsur hara dan air bagi tanaman. Hal ini dijelaskan oleh Vaulina (2002) bahwa jika kadar unsur hara dalam larutan tanah kurang maka unsur hara yang diadsorpsi akan dilepas secara perlahan. Dengan tersedianya unsur hara dan air, maka akan terjadi peningkatan penyerapan unsur hara sehingga tanaman akan lebih mampu memperbaiki pertumbuhan dan perkembangannya. 
Jurnal Media Pertanian Vol. 1 No. 2 Tahun 2016 Hal. 11 - 21

Media Komunikasi Hasil Penelitian dan Review Literatur Bidang Ilmu Agronomi ISSN $2503-1279$

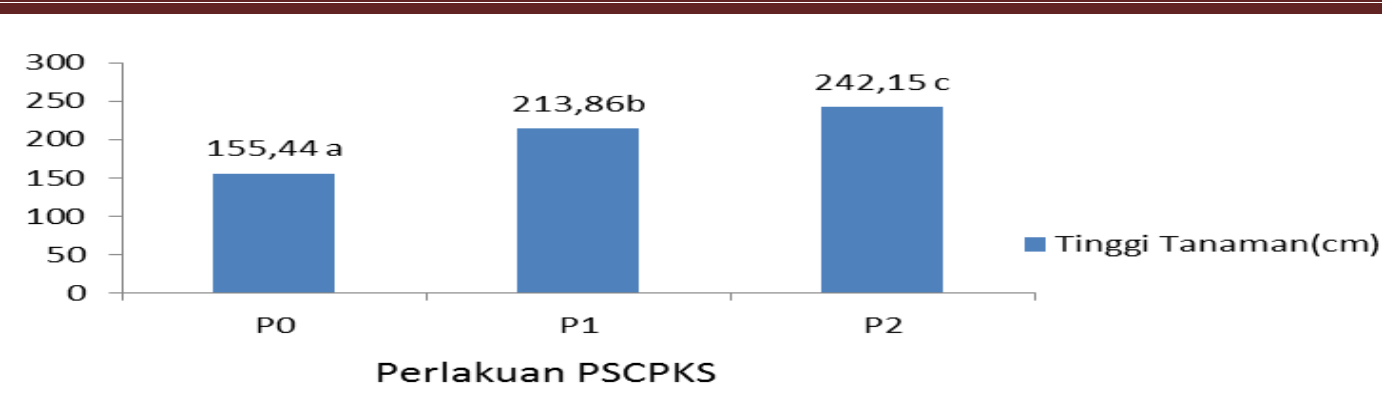

Gambar 1. Tinggi tanaman jagung umur 8 minggu setelah tanam terhadap pemberian PSCPKS plus zeolit.

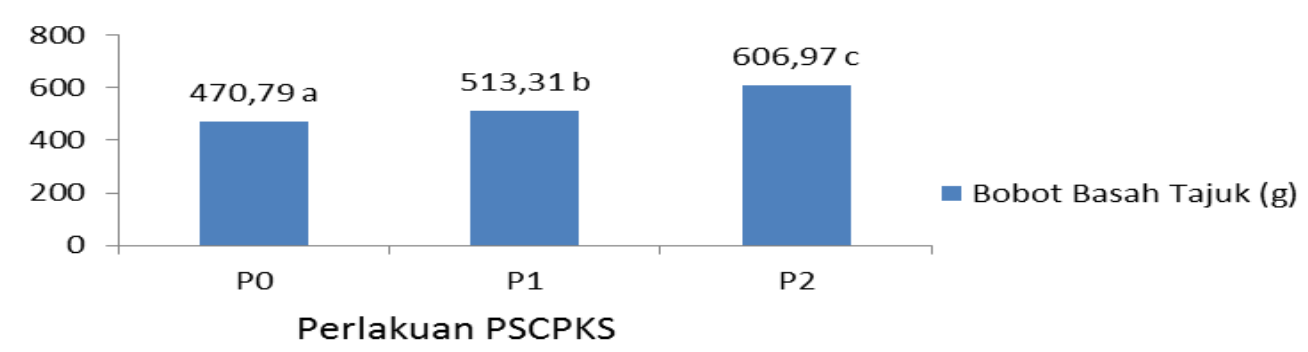

Gambar 2. Bobot basah tajuk tanaman jagung umur 8 minggu setelah tanam terhadap pemberian PSCPKS plus zeolit.

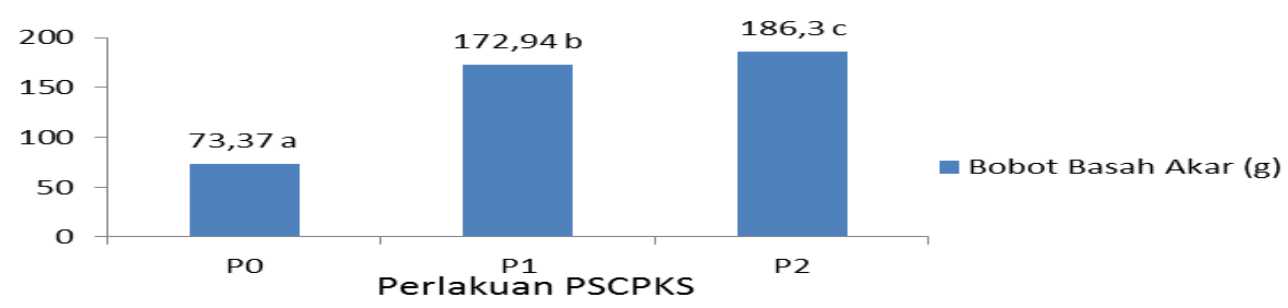

Gambar 3. Bobot basah akar tanaman jagung umur 8 minggu setelah tanam terhadap pemberian PSCPKS plus zeolit.

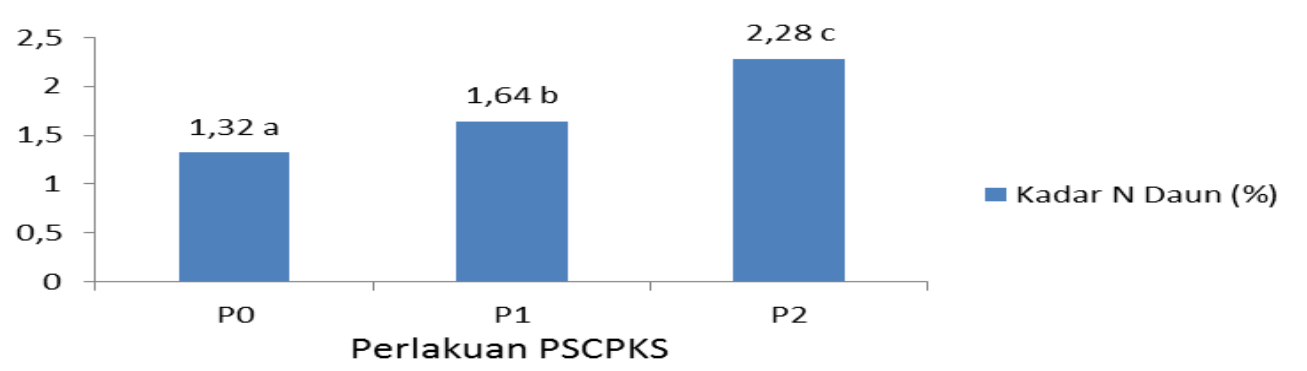

Gambar 4. Kadar $\mathrm{N}$ daun tanaman jagung umur 8 minggu setelah tanam terhadap pemberian PSCPKS plus zeolit. 
Jurnal Media Pertanian Vol. 1 No. 2 Tahun 2016 Hal. 11 - 21

Media Komunikasi Hasil Penelitian dan Review Literatur Bidang Ilmu Agronomi

ISSN $2503-1279$

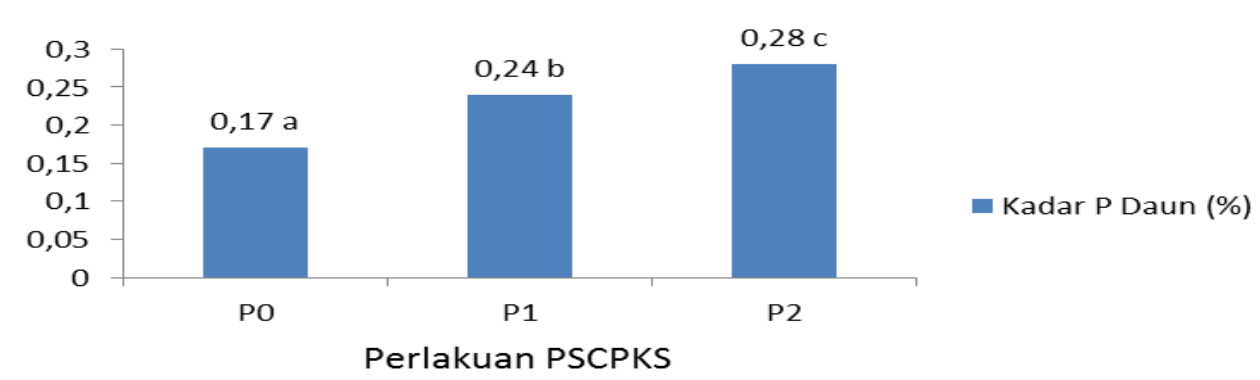

Gambar 5. Kadar P tanaman jagung umur 8 minggu setelah tanam terhadap pemberian PSCPKS plus zeolit.

Penelitian Abdullah dan Fitri (2004) mendapatkan bahwa pemberian zeolit pada tanah berpasir sebanyak 15\% dapat meningkatkan kapasitas daya pegang air tanah. Kemampuan zeolit dalam meningkatkan kadar air tanah tersebut dimungkinkan karena struktur zeolit berongga, sehingga zeolit mampu menyerap sejumlah besar molekul, seperti $\mathrm{H}_{2} \mathrm{O}$ yang berukuran lebih kecil atau sesuai dengan ukuran rongganya. Hal ini juga dijelaskan Mumpton (1997) ; Suwardi (2010) bahwa zeolit memiliki kemampuan menyerap dan mengeluarkan air serta menukarkan bagian kationnya tanpa merubah struktur kristalnya.

Produk samping cair pabrik kelapa sawit plus zeolit mampu berperan dalam mengatasi cekaman kekeringan seperti terlihat pada semua peubah morfologi, fisologi dan produksi tanaman jagung. Hal ini disebabkan peranan PSCPKS plus zeolit di dalam tanah sebagai pupuk organik penyedia hara tanaman (Kadar PSCPKS plus zeolit : $\mathrm{N}$ $0.29 \%$, P $0.09 \%$ dan $\mathrm{K} 0.1 \%$ ) dan dapat meningkatkan kapasitas daya pegang air tanah serta mengurangi kecepatan kehilangan air. Nursanti (2013) mendapatkan bahwa LCPKS plus zeolit dapat meningkatkan stabilitas makroagregat tanah dan kapasitas daya pegang air tanah sulfat masam potensial sampai masing-masing sebesar $22.59 \%$ dan 26.09\%. Selanjutnya Djajadi et al.(2010) menjelaskan bahwa pemberian bahan organik dan zeolit dapat mengurangi kecepatan kehilangan air pada tanah.

Tanaman yang diberi PSCPKS plus zeolit menunjukkan kapasitas yang lebih tinggi dalam memelihara kandungan unsur hara. Kapasitas yang lebih besar dalam penyerapan unsur hara dan transfor unsur hara dari akar ke tajuk berhubungan dengan peningkatan aktivitas akar. Tanaman yang diberi PSCPKS plus zeolit memberikan bobot basah akar dan bobot basah tajuk yang lebih tinggi dari pada yang tanpa pemberian PSCPKS dan pemberian PSCPKS tanpa zeolit. Dengan meningkatnya bobot basah akar berarti luasan perakaran yang dapat menyerap air dan unsur hara semakin banyak, sehingga dapat mencukupi kebutuhan air tanaman untuk aktivitas fisiologinya. Menurut Dubrovsky dan Go'mezlomeli (2003) bahwa strategi tanaman toleran menghadapi kondisi cekaman kekeringan dengan membentuk formasi akar yang dalam dan perabangan akar yang banyak.

Tanaman jagung membutuhkan paling kurang 13 unsur hara yang diserap melalui tanah. Hara N, P, dan K diperlukan dalam jumlah lebih banyak. Hara $\mathrm{Ca}, \mathrm{Mg}$, dan $\mathrm{S}$ diperlukan dalam jumlah sedang. Hara $\mathrm{Fe}, \mathrm{Mn}, \mathrm{Zn}, \mathrm{Cu}, \mathrm{B}, \mathrm{Mo}$, dan $\mathrm{Cl}$ diperlukan tanaman dalam jumlah sedikit. Unsur $\mathrm{N}, \mathrm{P}$, dan $\mathrm{K}$ diserap tanaman pada pertumbuhan fase 2, dan serapan hara sangat cepat terjadi selama fase vegetatif dan pengisian biji. 
Jurnal Media Pertanian Vol. 1 No. 2 Tahun 2016 Hal. 11 - 21

Media Komunikasi Hasil Penelitian dan Review Literatur Bidang Ilmu Agronomi ISSN $2503-1279$

Unsur $\mathrm{N}$ dan $\mathrm{P}$ terus-menerus diserap tanaman sampai mendekati matang, sedangkan $\mathrm{K}$ terutama diperlukan saat silking. Sebagian besar $\mathrm{N}$ dan $\mathrm{P}$ dibawa ke titik tumbuh, batang, daun, dan bunga jantan, lalu dialihkan ke biji. Sebanyak 2/3-3/4 unsur K tertinggal di batang. Dengan demikian, $\mathrm{N}$ dan $\mathrm{P}$ terangkut dari tanah melalui biji saat panen, tetapi K tidak (Olsen dan Sander, 1998).

Kadar $\mathrm{N}$ daun dan kadar $\mathrm{P}$ daun lebih tinggi pada perlakuan pemberian PSCPKS plus zeolit jika dibandingkan dengan perlakuan lainnya. Hal ini terkait dengan ketersediaan unsur hara yang ada di dalam tanah. Unsur hara berasal dari decomposisi dan mineralisasi yang membebaskan unsur-unsur di dalam tanah. Rosmarkam dan Yuwono (2008) menjelaskan bahwa proses mineralisasi tidak lepas dari aktivitas mikrobia tanah sebagai pendekomposisi dan melepaskan unsur hara ke larutan tanah. Peningkatan KTK pada kondisi air tersedia terjadi karena terpicunya mineralisasi dan aktivitas mikrobia tanah peningkat unsur hara tersedia tanah. Mariam dan Hudayana (2002) mendapatkan bahwa peningkatan KTK tanah dapat disebabkan antara lain oleh muatan negatif dari disosiasi gugus fungsional yang dihasilkan oleh mikrobia tanah, semakin banyak muatan negatif maka kation positif makin mudah dipertukarkan. Keizer dan Zech (1996); Ansori (2005) menambahkan bahwa meningkatnya KTK berarti bertambah pula muatan negatif tanah sehingga dengan demikian akan terjadi penolakan anion, hal ini berakibat pada peningkatan konsentrasi $\mathrm{P}$ dalam larutan tanah.

\section{KESIMPULAN}

Dari hasil penelitian dan pembahasan yang telah dilakukan dapat diambil kesimpulan bahwa pupuk produk samping cair pabrik kelapa sawit plus zeolit dapat mempengaruhi pertumbuhan tanaman jagung secara signifikan terutama pada tinggi tanaman, bobot basah tajuk, bobot basah akar, kadar $\mathrm{N}$ daun dan kadar P daun. Produk samping cair pabrik kelapa sawit plus zeolit $10 \%$ dosis $1000 \mathrm{ml} \operatorname{tanaman}^{-1}$ dapat lebih baik mempengaruhi pertumbuhan tanaman jagung.

\section{DAFTAR PUSTAKA}

Budianta,D. 2005. Potensi limbah cair pabrik kelapa sawit sebagai sumber hara untuk tanaman perkebunan. Dinamika Pertanian. 20(3): 273-282.

Babu. B.R, Meera.K.S, Venkatesan.P, and Sunandha.D. 2009. Removal of fatty acids from palm oil effluent by combined electro-fenton and biological oxidation process. Water Air Soil Pollut. 211: 203-210.

Edi.S, dan Salvia.V. 2011. Inovasi teknologi budidaya dalam rangka pengembangan usahatani jagung di Provinsi Jambi. Prosiding Pekan Serealia Nasional, Balai Pengkajian Teknologi Pertanian Jambi 2011.

Endro.K. 2008. Optimasi pemanfaatan zeolit alam dari gunung kidul untuk reduksi kadar cesium dalam limbah radioaktif. Prosiding Seminar Nasional Penelitian dan Pengelolaan Perangkat Nuklir, Batan, Yogyakarta

Jabri.A. 2008. Kajian metode penetapan kapasitas tukar kation zeolit sebagai pembenah tanah untuk lahan pertanian terdegradasi. Jurnal Standardisasi. 10(2): 56-69. 
Jurnal Media Pertanian Vol. 1 No. 2 Tahun 2016 Hal. 11 - 21

Media Komunikasi Hasil Penelitian dan Review Literatur Bidang Ilmu Agronomi ISSN $2503-1279$

Kundari.N.A, Susanto.A, Prihatiningsih.M.C. 2010. Adsorpsi Fe dan Mn dalam limbah cair dengan zeolit alam. Seminar Nasional VI Sdm Teknologi Nuklir Yogyakarta, 18 November 2010 . ISSN 1978-0176. Hal. 705-710.

Muzar.A. 2005. Aplikasi limbah cair pabrik kelapa sawit terhadap tanah ultisol dan pengaruhnya pada tanaman kedelai. Jurnal Agrivigor. 8(1): 24-32.

Nursanti.I, Budianta. D, Napoleon. A dan Parto.Y. 2013. Zeolite as a catalyst and nutrient adsorbent an organic fertilizer processing derived from palm oil mill effluent. Malaysian Journal of Soil Science. In press.

Olson.R.A, and Sander.D.H. 1988. Corn production. In Monograph Agronomy Corn and Corn Improvement. Wisconsin. p.639-686.

Rashid.S.S, Alam.Z, Ismail.M, Karim.A, Salleh.M.H. 2009. Management of palm oil mill effluent through production of cellulases by filamentous fungi. World $J$ Microbiol Biotechnol . 25:2 219-2226.

Singh.R.P, Ibrahim.M.H, Esa.N, and Iliyana.M.S. 2010. Composting of waste from palm oil mill: a sustainable waste management practice. Environ Sci Biotechnol . 9: $331-344$.

Vaulina. E. 2002. Potensi zeolit alam sebagai absorban logam-logam berat pada limbah perairan. Majalah Ilmiah Universitas Jenderal soedirman. Purwokerto. 2(28): 1-8.

Widiastuti.R, Suryanto.D, Mukhlis dan Wahyuningsih.H. 2006. pengaruh pemanfaatan limbah cair pabrik pengolahan kelapa sawit sebagai pupuk terhadap biodiversitas tanah. Fakultas Pertanian Universitas Sumatera Utara. http://www.google.com. (diakses 13 Desember 2011). 